\title{
Acidente rural ampliado: o caso das "chuvas" de agrotóxicos sobre a cidade de Lucas do Rio Verde- MT
}

\author{
Major rural accident: the pesticide "rain" case \\ in Lucas do Rio Verde city - MT
}

Wanderlei Antonio Pignati ${ }^{1}$

Jorge M. H. M achado ${ }^{2}$

James F. Cabral ${ }^{3}$

${ }^{1}$ UFMT/ISC.Universidade Federal de M ato Grosso/ Instituto de Saúde Coletiva. Av. Fernando Correia s/n, Coxipó. 78.060-900, Cuiabá MT. pignatimt@terra.com.br ${ }^{2}$ CESTEH/ENSP/FIOCRUZ

${ }^{3}$ FASE-M T
Abstract The article reports the environmental accident caused by aerial pesticide spraying that reached the urban space of Lucas do Rio Verde$M T$, in M arch 2006. It was characterized as a "major rural accident" of environmental and occupational aspects whose seriousness and extension crossed the agriculturally productive unit boundaries causing sanitary, social and environmental impact. This case study had as its objectivetheunderstanding of thesocial-technical scene of the accident and the monitoring process in health-environment in a research-action dynamic. The information was collected through interviews, documents and daily observation reports. It also referred to accidents, multidisciplinary and participatory analyses with the participation of local institutions of health, agriculture and environment, political and union leaderships, ranchersand farmers, the public prosecutor's office, journalists and the University. The study shows that the pesticide "use and abuse" monitoring actions have been extended to [a] "movement for thesustainable devel opment of the region" supported by the participative monitoring and the fight for democracy and social justice in the search of a sustainable agriculture and/or environment.

Key words M ajor rural accident, Pesticide, M onitoring in health-environment, Participative analysis
Resumo 0 artigo aborda 0 acidente ambiental causado por derivas de pulverizações aéreas de agrotóxico queatingiram o espaço urbano de Lucas do Rio Verde M T, em março de 2006. Caracterizou-secomo "acidente rural ampliado" decaráter ocupacional e ambiental, cuja gravidade e extensão ultrapassaram a unidade produtiva rural, causando impactos sanitários, sociais e ambientais. Este estudo de caso objetivou conhecer o cenário sociotécnico do acidente e o processo de vigilância em saúde-ambiente, numa dinâmica de pesqui sa-ação. As informações foram coIhidas através de entrevistas, documentos e registro de observações do cotidiano. Referenciouse ainda na análise interdisciplinar e participativa de acidentes, com envolvimento de instituições locais de Saúde, Agricultura e Ambiente, lideranças sindicais e políticas, chacareiros e fazendei ros, Promotoria de Justiça, jornalistas e a Universidade. 0 estudo mostra que as ações de vigilância do "uso e abuso" de agrotóxicos ampliaram-se para "movimento pelo desenvolvimento sustentável da região", apoiado na vigilância participativa, articulada com a luta pela democracia ejustiça social, na busca deuma agricultura e/ou ambiente sustentável.

Palavras-chave Acidente rural ampliado, Agrotóxico, Vigilância em saúde-ambiente, Análise participativa 
Introdução - "acidente rural ampliado" e metodologia da pesquisa-ação

Os acidentes em saúde-ambiente são entendidos pelo senso comum como eventos anormais e súbitos que cau sam danos materiais e/ou humanos e/ ou ambientais. Os acidentes são previsíveis na maioria das ocorrências ligadas ao processo produtivo. Entretanto, seus impactos e danos dependem de condições anteriores que, no caso rural, estão vinculadas à agroindústria ou à "moderna agricultura" com suas novas tecnologias e dependência de agroquímicos.

Os acidentes com agrotóxicos estão intrinsecamente relacionados ao efeito esperado destas substâncias, pois com a finalidade de combater as "pragas da lavoura", o homem contamina intencionalmente o local de trabalho, que é o próprio ambiente agrícola, atingindo em maior ou menor intensidade os trabalhadores, a produção e o meio ambiente.

As aplicações de agrotóxicos nas monoculturas de M ato Grosso são feitas através de pulverizações por tratores ou por aviões agrícolas, onde asnévoas deagrotóxicos, além deatingirem 0 alvo (plantas e pragas), também atingem os trabal hadores e, indiretamente, 0 ar/solo/água, os moradores, os animais e outras plantas que estão no entorno das "áreas tratadas".

Como na maioria dos municípios matogrossenses predomina o processo produtivo denominado de "agricultura moderna", o cotidiano da população é a convivência com tratores, pulverizadores e seus ruídos e com os odores dosfertilizantes eagrotóxicos; porém, isso éjustificado como necessário ao desenvolvimento econômico ${ }^{1,2}$.

Em Lucas do Rio Verde-MT, no caso estudado, em março de 2006, a população urbana observou que névoas de agrotóxicos oriundas de pulverizações aéreas danificaram hortaliças e plantas ornamentais de ruas e quintais da cidade. Este fato motivou o Sindicato de Trabalhadores Rurais a convidar o Instituto de Saúde Coletiva (ISC/UFMT) e a Federação de Órgãos para Assistência Social e Educacional (FASE-MT) a colaborarem na avaliação do risco ocupacional e ambiental e na busca de medidas de mitigação, prevenção e controle.

N os primei ros relatos dos diretores do Sindicato, anterior à ida ao acampo ou na fase de elaboração do projeto, percebeu-se: a) que a complexidade da situação sanitária ultrapassava as possibilidades de solução em curto ou médio prazo; b) a incerteza quanto ao envolvimento dos órgãos estatais em implementar novas medidas de vigilância à saúde no município/região; c) a necessidade de desencadear um movimento social em defesa da saúde humana e ambiental.

Caracterizou-se este tipo de acidente como "acidente rural ampliado", de caráter ocupacional e ambiental, cuja gravidade e extensão ultrapassam o local de trabalho, extrapolando os riscos para além da unidade produtiva rural, com provável contaminação do ar, mananciais deágua, solo e das plantas, animais e população da cidade. Além de o agrotóxico ter colocado a comunidade em situação de risco à saúde no momento do acidente, supôs-se também que outros efeitos conhecidos e/ou imprevisíveis poderiam aparecer tardiamente, ultrapassando os limites temporais.

Esta adjetivação de rural ampliado faz um paralelo com a definição clássica de "acidente químico ampliado", caracterizado e anal isado por Freitas et al ${ }^{3,4}$, relacionado aos acidentes que ocorrem demaneira aguda nos processos de produção industrial urbano, causando grande impacto sanitário e ambiental, como os vazamentos e/ou explosões em indústrias químicas, petroquímicas enucleares e derramamentos abruptos de produtos químicos em acidentes de transporte.

A classificação de "acidenterural ampliado" foi necessária para identificar estetipo de acidente com as características comuns referidas e possibilitar, posteriormente, análise de tendência de séries históricas dos casos, pois em epidemiologia o termo "acidente em geral" é uma abstração jurídica 5 .

A partir de ações integradas de vigilância ambiental e de saúde do trabalhador, a Saúde Coletiva propicia uma nova visão de conhecimentos e práticas que abrange a inter-relação produção-ambiente-saúde. Isso implica metodologia de ação e análise que, pelas características do seu objeto, no caso o acidente rural ampliado, requer uma abordagem interdisciplinar ea incorporação do saber e partici pação daqueles que vivenciam e se encontram expostos aos riscos, conforme indicam Porto et al. ${ }^{6}$, TambeIlini et al. ${ }^{7}$, Soares et al. ${ }^{8}$, Herculano et al. ${ }^{9}, \mathrm{Au}$ gusto et al. ${ }^{10}$, M inayo et al. ${ }^{11}$ e Breilh ${ }^{12}$.

Para a superação dos limites atuais de análise deacidente ambiental/ocupacional, indo além da tradicional vigilância em saúde que investiga os "atos inseguros" ou as "condições inseguras", é necessário buscarmos as causas subjacentes de natureza organizacional/gerencial esocial/econômica, por meio deabordagens "sociotécnicas" dos 
sistemas geradores de riscos, como proposto na metodologia de "Análise Interdisci plinar e Participativa de Acidentes (AIPA)" desenvolvida por $M$ achado et al. ${ }^{13}$. Tal metodologia trata estes acidentes como fenômenos de saúde pública, analisando-os com participação ativa dos afetados/ agravados e dos pesquisadores, num processo de vigilância em saúde, em cooperação com a sociedade organizada, avançando na perspectiva de um gerenciamento de riscos participativo, com val orização da memória e conhecimento dos trabalhadores e população.

Esta abordagem, que orientou a descrição e análise do caso do acidente de Lucas do Rio Verde, considera o contexto sociotécnico da produção deste tipo de evento e os impactos do crescimento econômico que devastam os recursos naturais, deteriorando a saúde humana e ambiental. D esta forma, descreve-se o padrão de produção local/regional, seus riscos ocupacionais e ambientais e seus mecanismos de regulação e controle. Esta "pesquisa-ação" tem como estratégia o desenvolvimento de ações de vigilância à saúde e ambiente que envolve, de forma participativa e integrada, as instituições locais e regionais de Saúde, Agricultura e Ambiente, lideranças sindicais, políticas e comunitárias, chacareiros e fazendeiros, jornalistas, Promotoria de Justiça e a Universidade.

Neste processo, destacamos os seguintes procedimentos: a) análise do contexto sociotécnico do processo produtivo, com coleta de dados secundários; b) participação ativa no processo de vigilância à saúde com intervenção/cooperação; c) observação direta das ações cotidianas e públicas registradas em diário de campo; d) depoimentos e entrevistas registrados em vídeos e fitas cassetes com diretores de colégios, representantes do Sindicato, da UFM T, da FASE, das Secretarias de Saúde, Agricultura e Ambiente, de vários chacareiros e de fazendeiros; e) análise documental com basena hermenêuticadialética.

0 estudo dos impactos do desenvolvimento agroindustrial na saúde-ambiente com suporte teórico-metodológico na AIPA de Machado et al. ${ }^{13}$, na pesquisa-ação de Thiollent ${ }^{14}$ e na análise documental de Minayo ${ }^{15}$ consta no projeto de pesquisa, aprovado pelo Comitê deÉtica em Pesquisa da EN SP/FIO CRUZ (parecer no 83/2005), que contempla pesquisa em vigilância em saúde, na região onde ocorreu 0 acidente rural ampliado estudado.
O contexto sociotécnico: a agroindústria (insustentável) de Lucas do Rio Verde

As constantes mudanças nos processos produtivos, amplificadas com a industrialização, acarretaram grandes transformações nos espaços urbano, rural e florestal. A agricultura, que por sé culos se constituiu em subsistência ou meio de vida dos pequenos agricultores, sofreu mudanças induzidas pelo agronegócio, que orienta a produção para o mercado, influenciado pelo lucro e amparado no subterfúgio da "necessidade de alimentar a população mundial" em constante expansão.

Desta forma, o processo de produção agropecuário vem sofrendo importantes mudanças tecnológicas e organizacionais, no sentido de aumentar a produtividade, começando pela substituição da mão-de-obra pela maquinaria, passando pela introdução dos fertilizantes químicos e agrotóxicos, chegando ao final do século passado a introduzir a biotecnologia e o uso da informática.

Estemodelo deagricultura, acompanhado de crédito rural e subsídios públicos, geralmente induz os fazendeiros a ignorarem os desgastes dos recursos naturais, tornando as práticas agrícolas poluidoras edegradadoras, as mais lucrativas em curto prazo, segundo Garcia ${ }^{16}$. No entanto, essa agricultura, principal atividade do desenvolvimento agroindustrial-florestal de M ato Grosso, trouxe o aumento da produtividade rural, mas tem provocado exclusão social, migração rural, genocídio indígena, trabalho escravo, desemprego, concentração de renda, empobrecimento da população rural remanescente e danos à saúde humana e ambiental regional 1,2,17,18,19.

Trata-se de um processo de insustentabilidade ambiental: na primeira etapa se desmata/destrói o cerrado e/ou a floresta; numa segunda fase seimplanta um sistema agropecuário dependente de alta tecnologia, de equipamentos e de sementes híbridas ou transgênicas dependentes de agrotóxicos e fertilizantes químicos para se desenvolverem; como conseqüência, a terceira etapa deste processo provoca danos imediatos (agudos) el ou tardios (crônicos) à saúde humana e ambiental ou cria situações de riscos para além dos locais das plantações agrícolas, ampliando os agravos, com impacto negativo social, sanitário e ambiental.

É interessante observar que a aplicação de agrotóxicos é, provavelmente, a única atividade em quea contaminação do ambiente de trabalho é intencional, ou seja, uma finalidade sendo pro- 
vocada pelos fazendeiros, "no intuito de combater as pragas da lavoura". Entretanto, o mais grave disto é que na agricultura o ambiente de trabalho é o próprio meio ambiente. Portanto, se contaminam o trabalhador, a própria produção e o meio ambiente.

Como prevenir as poluições e contaminações? "Normalmente, as contaminações dos ambientes de trabalho são indesejáveis e devem ser controladas, mas como proceder quando a contaminação é a finalidade da atividade?", comenta Garcia ${ }^{16}$. Para a prevenção destes riscos, Gar$\mathrm{cia}^{20}$ recomenda, como medida fundamental, a adoção de práticas agrícolas que propiciem a redução da incidência de pragas e que "se houver necessidade de uso de um agrotóxico, isso se dê dentro dos critérios agronômicos, ambientais e de saúde mais rígidos possíveis (o que raramente acontece)".

Dentre os agravos à saúde relacionados ao processo produtivo rural, os de maior relevância e impacto negativo para a saúde humana e ambiental são as poluições e/ou contaminações e intoxicações agudas e/ou crônicas, relacionadas aos agrotóxicos. Devido às dificuldades de percepção dos riscos, os agrotóxicos atingem de maneira imediata os trabal hadores que vendem, transportam, manipulam/pulverizam estes insumose, indiretamente, suas famílias, que moram "dentro das plantações" e higienizam as roupase EPIs (Equipamentos de Proteção Individual dos trabal hadores, assim como através do armazenamento desses produtos dentro ou próximo de suas residências ${ }^{21,} 22,23$.

Ao mesmo tempo, o homem, outros animais, vegetais e 0 ar/solos/águas do entorno das pulverizações também são atingidos, seja pelo deslocamento de parte dos agrotóxicos através do ar/ vento, água e alimentos contaminados ou pelos constantes desvios/derivas das pulverizações que ocorrem em cada ciclo das lavouras. Além disso, o uso intensivo de agrotóxicos pode promover 0 adoecimento e extinção de espécies animais e vegetais, assim como o aumento de populações de pragas resistentes.

No M ato Grosso, maior consumidor nacional deagrotóxico ( $19 \%$ do usado no Brasil), foi utilizado/comercializado na safra de 2005 um total de 1,3 bilhões de dólares segundo o SIN $D_{A A}{ }^{24} \mathrm{e}$, segundo o somatório das segundas vias dos receituários agronômicos feito pelo Sistema de Informação de Agrotóxico do Instituto de Defesa Agropecuária de M ato Grosso - IN DEA-M T ${ }^{25}$, foi aplicado nesse ano cerca de 48 mil toneladas de agrotóxicos (produto comer- cial). A utilização desse volume de agrotóxico, aliado aos fertilizantes químicos e à adoção de novas tecnologias e organização do trabalho, fez de M ato Grosso o maior produtor brasileiro de soja, al godão e gado bovino e o segundo de miIho e arroz ${ }^{26}$.

Vários municípios mato-grossenses são grandes produtores agrícolas, com destaque para Lucas do Rio Verde, localizado a $380 \mathrm{~km}$ ao norte deCuiabá, fundado em 1988, no processo deocupação do cerrado para implantação da agropecuária, contando hoje com 29.089 habitantes ( $15 \%$ rural). Porém, dos seus 367 mil hectares de área, restam apenas $14 \%$ de cerrado nativo que também está impactado pelas agressões do desenvolvimento local/regional citado ${ }^{27}$.

Durante o ano de 2005, esse município cultivou e/ou produziu: a) soja: 200.500 hectares, com produção de 697.800 toneladas ( 60 produtor de MT); b) milho: 140.000 hectares, com produção de 588.000 toneladas ( 1 o produtor de MT); c) arroz: 1.400 hectares ou 4.872 toneladas; d) algodão: 5.000 hectares ou 18.271 toneladas; e) sorgo: 10.000 hectares ou 30.000 toneladas; f) feijão: 310 hectares ou 837 toneladas; g) tomate: 8 hectares ou 188 toneladas; h) bois: 20.501 cabeças; i) suínos: 32.988 cabeças; j) vacas leiteiras: 1.233 cabeças, com produção de 2.811 .000 litros de leite; $k$ ) hortal iças: 82 chácaras de hortifrutigranjeiros de produção familiar (todos usam agrotóxicos); I) horto de plantas medicinais, com 180 canteiros de diferentes plantas, cultivadas sem uso de agrotóxicos, que fornece insumos fitoterápicos para toda região $0^{28}$.

Atual mente, a industrialização dos produtos agropecuários se restringe ao leite, mas o município possui um complexo de silos de cereais de várias empresas de agronegócios (Cargil, Bunge, Amagi, Sadia) e encontra-se em fase de implantação de uma agroindústria de suínos/aves e outra de farelo/óleo de soja $a^{28}$.

A posse da propriedade da terra é bastante concentrada e desigual, ou seja, $60 \%$ da área ocupada são de fazendas acima de 1.000 hectares, $30 \%$ de 100 a 1.000 hectares e $10 \%$ abaixo de 100 hectares, incluindo-se nestas últimas 82 chácaras dehortifrutigranjeirose 205 chácaras deagricultura familiar (4 hectares cada); todas tendo em comum o uso de agrotóxicos e fertilizantes químicos ${ }^{28}$.

Como a produção agrícola é dependente de alta tecnologia agroquímica, utilizou-se em 2005, nestemunicípio, segundo o somatório das segundas vias do receituário agronômico fornecidos pelo INDEA-M T ${ }^{25}$, um total de $2.978 .851 \mathrm{~kg}$ de 
agrotóxicos ( produto comercial), assim distribuídos: $61 \%$ de herbicida, $18 \%$ de inseticida, $14 \%$ de fungicida e $7 \%$ de outros tipos. Deduziu-se uma média de aplicação e/ou consumo de 8,5 kg de agrotóxicos por hectare plantado, ou exposição de $102 \mathrm{~kg}$ de agrotóxico por habitante/ano ou $682 \mathrm{~kg} / \mathrm{habitante}$ rural/ano. Além disso, potencialmente a população de Lucas do Rio Verde se expôs aos agrotóxicos 6 vezes mais que a mé dia estadual ( $17 \mathrm{~kg} / \mathrm{habitante} / \mathrm{ano}$ ) ou 8 vezes mais que a média por habitante rural de $M$ ato Grosso ( $85 \mathrm{~kg} /$ habitante rural/ano). No município, usou-se, segundo o SINDAG ${ }^{29}$, quase três vezes mais agrotóxico quea média brasileira, que é de 3,2 kg de agrotóxico/hectare plantado/ano.

Ao longo do tempo, as condições para um acidente rural ampliado têm sido dadas por esse cenário, onde os fazendeiros contaminam intencionalmente, com agrotóxicos, 0 ambiente detrabalho, que é o próprio meio ambiente onde se pratica a agricultura. Somam-se a isso os riscos do transportee do armazenamento inadequados, dos destinos irregulares das sobras e vasilhames, além da limpeza inadequada dos equipamentos eEPIs.

Indaga-se também: qual é o destino final do volume total de agrotóxicos utilizados durante os últimos dezoitos anos nas lavouras do município? Onde foram parar seus resíduos? Quantos cânceres, teratogêneses, desregulações endócrinas e distúrbios neurológicos e psiquiátricos eles promoverão e/ou induzirão a médio ou longo prazo?

Embora os trabalhadores rurais e o restante da população (indiretamente) estejam submetidos cotidianamente à exposição de diferentes tipos de agrotóxicos é, provavelmente, nos casos mais drásticos de intoxicações agudas humanas e/ou ambientais, como o "acidente ampliado rural" relatado neste artigo, que se evidenciam os riscos a que eles estão submetidos nesse dia-a-dia.

A "chuva" de agrotóxico e a análise interdisciplinar e participativa do acidente

A complexidade da relação produção-saúde-ambiente na "moderna agricultura" foi constatada, por exemplo, pelas maneiras como são realizadas as pulverizações aéreas ou por trator para dessecar soja para a colheita: a) pulverizando-se próximo às moradias e cursos d'água; b) não se notificando às autoridades sanitárias os acidentes de derivas dos agrotóxicos; ou c) amplifican- do as poluições usando-se herbicidas de maior toxidade (classe I) com justificativas de se dessecarem asfolhas da soja mais rapidamente, em dois dias, enquanto que os de classe IV dessecam em dez dias; conforme análise de relatos das entidades entrevistadas.

Na primeira reunião dos técnicos da UFM T e da FASE com representantes do Sindicato de Trabalhadores Rurais, da Associação dos Chacareiros e do Horto de Plantas M edicinais, estas entidades locais relataram nas entrevistas quedois dias após as nuvens ou 'chuvas' de agrotóxicos oriundos de pulverizações aéreas atingirem a cidade, observaram que secou ou queimou a maioria das plantas de 65 chácaras de hortaliças e legumes ( localizadas em vários pontos da periferia da cidade), secou a maioria das folhas das plantas do horto com 180 canteiros de diferentes espécies de plantas medicinais (localizadas quase no centro da cidade) equeimou 'sal picado' milhares de plantas ornamentais das ruas e quintais da periferia e do centro da cidade.

As entidades citadas acima, ao serem novamente entrevistadas e questionadas se haviam notificado o caso às autoridades sanitárias ou judiciais, informaram que até aquele momento (oito dias após) ainda não haviam feito a notificação porque ainda estão construindo um movimento para a denúncia. Relataram ainda que este fenômeno é corriqueiro e acontece todos os anos, mas que este ano ele foi mais forte e por isto resolvemos pedir ajuda porque não agüentamos maise que sozinhos não iríamos solucionar o problema. Também informaram que determinado chacareiro acionou na justiça, um grandefazendeiro desoja, porque seu avião queimou com agrotóxico toda sua plantação de melancias quando o fazendeiro dessecava soja e após semanas, o IN DEA-M T realizou uma perícia ambiental no local, mas até hoje nada de resolução, porém, o fazendeiro 0 ameaçou de morte se ele continuasse com a ação na justiça".

Será que este processo produtivo agropecuário não contempla a valorização da saúde e da vida? Por que o movimento social/popular não rompe o círculo dessa desregulamentação prejudicial à saúde e ambiente? O u será que o Estado, enfraquecido, está refém dos poderes financeiros e comerciais? São questões que não requerem respostas imediatas, mas que exigem debate, reflexão e ação, de modo a orientar o fim da degradação ambiental e da saúde.

Os representantes das entidades presentes naquela primeira reunião, em conjunto com a equipe da UFMT/FASE, visitaram e avaliaram, por amostragem aleatória simples, seis chácaras 
hortifrutigranjeiras e o horto medicinal atingidos, confirmando as observações feitas em depoimentos anteriores. Nas entrevistas feitas com vários agricultores, estes fizeram as seguintes observações: nós ficamos espantados porque queimou grandequantidadede plantas, muito maisque das outras vezes [...] mas perguntamos o queaconteceria se não tivesse queimado tanto? e indagaram: quando despejam nuvens de inseticidas que não queimam as plantas, nós agüentamos o cheiro elogo esquecemos; quais os riscos que corremos? 0 presidente do Sindicato complementou: e aqueles venenos que não têm cheiro, mas ficamos respirando diariamente aqui na cidade ou na roça, será que não faz mal? Enquanto que outros chacareiros visitados e entrevistados, concluíram que 0 agrotóxico não devefazer mal pra genteporquenós somos mais fortes que as folhas de alface e outros expressaram que na sua família nunca ninguém morreu por causa dos venenos. Uma agricultora se expressou da seguinte maneira em sua entrevista: também uso vários tipos em minha horta, só que na hora certa; porém, se estivesse usando dessecante no momento do acidente do avião não teria notado, além disso, só uso veneno defaixa verde que não mata as plantas ou gente, mas aquele do avião deve ser dos fortes, de faixa vermelha ou preta.

O bservou-se que a comunicação de risco sobre os agrotóxicos é muito variada, mas todos mostraram que são carentes de informações técnicas sobre seus impactos negativos na saúde. Segundo Perez et al. ${ }^{21}$, Stoppelli et al..$^{22}$ e Silva et al. ${ }^{23}$, vários fatores socioeconômicos influenciam no perfil de percepção de risco daqueles queusam agrotóxicose, conseqüentemente, no grau de suas exposições aos agrotóxicos; além disso, as comunicações de riscos feitas pelos agrônomos e vendedores são falhas ou de difícil apropriação pela maioria dos trabalhadores rurais.

Estimuladas com a participação da Universidade, aquelas três entidades locais citadas resolveram iniciar um movimento social, no sentido de mitigar os danos na saúde humana eambiental ou no reparo da perda econômica desuas plantações agrícolas, denominando-o de "vigilância do uso e abuso de agrotóxico no município". Os primeiros participantes do movimento decidiram deflagrar o processo pela notificação à vigilância sanitária/ambiental das Secretarias Municipal e Estadual de Saúde; posteriormente notificaram a Secretaria M unicipal de Agricultura e Ambiente, o Prefeito e a Procuradoria de Justiça. Exigiram daquelas entidades a análise, aval iação e miti gação dos danos à saúde huma- na eambiental, além da implementação do processo participativo de vigilância à saúde-ambiente ora desencadeado, conforme relato das entidades entrevistadas.

$\mathrm{Na}$ investigação do caso, a Secretaria M unicipal de Agricultura/Ambiente e a Promotoria de Justiça concluíram, expressando em entrevista, que possi velmente se tratava de um acidenteresultante deuma deriva de um herbicida deamplo espectro, usado para dessecar soja para a colheita através de pulverizações aéreas e/ou terrestre, que foi trazido pelo vento de plantações do entorno da cidade. Também relataram que a maior preocupação no momento era encontrar os responsáveis pela deriva dos agrotóxicos, para ressarcimento dos prejuízos aos chacareiros. No dia seguinte, aquelas instituições convocaram os pilotos de aviões agrícolas da região e, segundo relato do representante do Sindicato que presenciou a reunião, sua conclusão foi a seguinte: os vários pilotos se uniram e não se delataram, disseram que foi um acidente, culpou-se o vento que mudou de repente e que não havia provas concretas.

A Secretaria Municipal de Saúde, auxiliada pela Estadual, ambasnotificadas, informaram, em entrevista, que investigariam o caso, levantariam os dados de intoxicações e analisariam os resíduos de agrotóxico nas fontes de água potável da cidade (poços artesianos). 0 representante da Prefeitura Municipal analisou a situação e relatou na entrevista que o herbicida do acidente ou deriva do avião foi o 'paraquat', quenão fará mal e não matará ninguém em Lucas, pois este defensivo é muito usado para fazer a capina química em todas as ruas da cidade e nunca aconteceu nada.

O Sindicato dos Trabalhadores elaborou boletim informativo sobre o caso e divulgou amplamente as informações repassadas pela equipe da UFMT/FASE e os encaminhamentos dados pelas instituições notificadas. 0 jornal e a rádio FM locais divulgaram trechos sintéticos do boletim como notícias, ao mesmo tempo em que divulgaram a posição da Prefeitura e dos fazendeiros preocupados com "os prejuízos econômicos que tais notícias poderiam trazer para as exportações de seus produtos agrícolas". (conforme relato do jornalista entrevistado).

A Câmara Técnica Estadual de Agrotóxicos MT, provocada pela notificação, se reuniu 25 dias após 0 acidente, colheu dados e depoimentos e informou na reunião que provavel mente se tratava de uma deriva de agrotóxico, mas que não havia provas laboratoriais de resíduos nas plantas. Também se relatou que aguardavam os resultados das análises de resíduos na água, solicitados pela 
Secretaria de Saúde. 0 representante técnico do Ministério da Agricultura, que periciou o local e colheu amostras das plantas, oito dias após o acidente, informou na reunião que se tratava de uma deriva de pulverização por herbicida que afetou as plantas do entorno da cidade, mas que não se analisou resíduos de agrotóxicos. 0 representante do Sindicato das Indústrias de Defensivos Agrícola (SINDAG) propôs e foi acatado por unanimidade dos membros ali reunidos, que sua entidade farátreinamentos para os pulverizadores da região, defendendo como causa básica do acidente, a falta de capacitação técnica dos pilotos. Além dessa medida, indicou-se que a Secretaria Estadual de Saúde deverá implantar o Programa deAnálise de Resíduos de Agrotóxico (PARA) ampliado para água, leite e outros alimentos e que a Prefeitura deverá colaborar na fiscalização sanitária agropecuária e ampliar a vigilância à saúde e ambiente, realizada em Lucas do Rio Verde (conforme entrevista do representante da UFM T que participou desta reunião).

Deriva acidental ou desvio técnico de pulverizações de agrotóxicos? Problema freqüentecom os agrotóxicos no M ato Grosso é a "deriva" nas pulverizações aéreas ou com trator, as quais são definidas pelos agropecuaristas ou pelas indústrias de agrotóxicos como um acidente e/ou erro de alvo na aplicação e/ou falta de treinamento e/ ou descuido e/ou um ato inseguro, culpabilizando o trabalhador que desejava pulverizar uma área eo vento ou a chuva conduziu o veneno para outro local. Entretanto, a Empresa Brasileira de Pesquisa Agropecuária acrescenta que exi stenormalmente uma "deriva técnica", como explicita $\mathrm{Chaim}^{30}$, que os atuais equipamentos de pulverização, mesmo com calibração, temperatura eventos ideais, deixam cerca de $32 \%$ dos agrotóxicos pulverizados retidos nas plantas, $49 \%$ vão para 0 solo e $19 \%$ vão pelo ar para outras áreas circunvizinhas da aplicação. Além disso, há pulverizações em plantações próximas às residências e córregos, desrespeitando a proibição de pulverização próxima de fonte de água, córregos/rios e residências, como preconiza o código florestal e a lei dos agrotóxicos.

Na segunda reunião ou audiência pública, convocada pelas instituições públicas da cidade, realizada 38 dias após o acidente, a Secretaria Municipal de Saúde comunicou que não constatou uma epidemia de intoxicação aguda em humanos, baseando-se nas notificações obrigatórias de casos de intoxicações ao SU S/SINAN ${ }^{31}$ que registrou apenas dois casos no município nos últimos cinco anos e nenhum no ano de 2006.
Informou ainda que na análise de resíduos de agrotóxicos da água potável não se encontrou 0 "paraquat", único agrotóxico pesquisado. 0 representante da Secretaria foi questionado a respeito da amostra deágua ter sido colhida somente vinte dias após o acidente e por que se analisou apenas um herbicida específico, mas não se obtiveram as respostas necessárias. A associação dos chacarei ros informou na reunião e em entrevista que os agricultores continuaram a vender as verduras que sobraram, pois eram folhas e frutos novos e sadios. $O$ representante do Horto M edicinal local informou quese podaram todasas plantas afetadas eesperam-se novos brotos para se usar como fitoterápicos. Um grandefazendeiro comentou que este tipo de acidente é comum na região, ocorrem todos os anos ea culpa éda ganância pelo lucro rápido de alguns fazendeiros, do descuido el ou falta de treinamento dos pilotos e ausência de fiscalização. Um vereador presente na reunião discordou da não existência de casos de intoxicação durante este ano, pois informou que visitou vários el eitores internados por intoxicação com agrotóxicos este ano. A pós este diálogo, um técnico da vigilância sanitária do município comunicou que na análise epidemiológica que se realizou houveum número acima da média de casos de rotaviroses notificados naquela semana do acidente e que os diretores dos dois hospitais do município impediram-no de analisar os prontuários na busca decasos deintoxicação por agrotóxicos (conforme gravação da reunião com filmadora, autorizada pelo Vereador e representantes da UFMT, da FASE, do Sindicato, dos Chacareiros, do H orto M edicinal e da Secretaria de Saúde).

Nesta segunda reunião, notou-sequedos chacareiros que haviam sido convidados, apenas compareceram o presidente da associação e dois agricultores. 0 presidente informou na entrevista que, a maioria dos chacareiros foi procurada por 'políticos' que solicitaram para não comparecerem à reunião, pois se o fizessem teriam seus produtos embargados pela vigilância sanitária econseqüentemente a prefeitura não mais compraria suas hortaliças para a merenda escolar.

Portanto, o Estado teria encerrado mais um caso de "deriva" de agrotóxico no Mato Grosso sem os devidos esclarecimentos esem implementar todas as medidas necessárias de mitigação dos danos ou de preven ção de acidentes ou de poluição ocupacional e ambiental. Além disso, descumpriram-sevários procedimentos inscritos em N ormas e Rotinas, tanto de investigação epidemiológi ca ${ }^{32}$ como de análise de resíduos de agrotóxicos em águas e alimentos ${ }^{33}$. 
Entretanto, alguns diretores de escolas, centros acadêmicos estudantis e a O rganização Luverdense de M eio Ambiente (OLUMA), que participaram das ações de vigilância, compareceram à sede do Sindicato dos trabal hadores rurais e solicitaram parceria para "caminharem" para além da vigilância do "uso e abuso" de agrotóxicos, ampliando para "movimento pelo desenvolvimento sustentável de Lucas do Rio Verde e região".

\section{A implantação do movimento pelo desenvolvimento sustentável}

N ovamente, a Universidade e a FASE foram convidadas pelo Sindicato de Trabalhadores Rurais para participarem da análiseemanejo do acidente para além da "vigilância dos agrotóxicos", caminhando no sentido da organização do movimento pelo desenvolvimento sustentável em Lucas do Rio Verde.

Avaliou-se, conjuntamente, que seria um movimento de transformação da realidade complexa e diversa, que não tem encontrado espaço no exercício das políticas públicas, sejam nos "bancos escolares" tradicionais ou no setor de serviços de saúde eambiente. Entendeu-se como um movimento social decaráter mais amplo que a educação ambiental ou vigilância à saúde, que requer conscientizar-se que 0 ambiente atual é um espaço socialmente construído, como define Santos $^{34}$, e que o mesmo pode ser reconstruído para ser sustentável e ocupado pela maioria da população, desde que a educação seja compreendida como ato político de práxis libertadora, como entende Freire ${ }^{35}$.

Iniciaram-se as ações buscan do estratégias de ampliação das parcerias, buscando-as, naquele momento, junto aos Conselhos Municipais de Saúde, Ambiente e Educação. Através de conseIheiros, conseguiu-se pautar e discutir o assunto/problema dos agrotóxicos e do "desenvolvimento insustentável" do município. Da análise das entrevistas com os Consel heiros, concluiu-se que: os consel heiros não detêm informações técnicas so bre os impactos sociosanitários dos agrotóxicos; que há desconfiança quanto à capacidade técnica daqueles serviços de solucionarem os problemas de saúde-ambiente; que não há articulação entre os três serviços e conselhos e que inexistem diretrizes e propostas sobre 0 assunto/ problema inscritas nos planos municipais. A maioria dos conselheiros mostrou interesse em participar do movimento.
Em seguida, para ampliar o movimento, ultrapassar as "barreiras" locais da mídia e produzir recursos de divulgação e conscientização, articulou-se com a Radiobrás, que enviou uma equipepara a cidade, onde realizaram várias entrevistas, produziram videoclipes, noticiários e editaram uma curta metragem sobre 0 acidente, incluindo-os num portal eletrônico do site da Radiobrás ou da Agenciabrasil: especiais/ agrotóxico ${ }^{36}$.

Posteriormente, o M inistério Público Estadual, em Cuiabá, foi notificado e acionado pelo movimento, queconvocou, em junho/2006, uma audiência pública com entidades, chacareiros, fazendeiros e população, onde se concluiu que 0 evento foi uma deriva acidental de pulverização de agrotóxico. Nesta mesma reunião, o M inistério promoveu um "Termo deAjuste de Conduta" junto aos fazendei ros e pilotos de aeronaves agrícolas da região e solicitou da UFM T que se realizasse uma perícia ambiental na área do acidente, conforme relatos dos representantes da UFMT, da FASE e do Sindicato entrevistados.

O movimento organiza-se no município liderado pelo Sindicato de trabalhadores rurais, diretores escolares ecentros acadêmicos estudantis, que já promoveram várias reuniões e mesas redondas com autoridades sanitárias e ambientais, com trabalhadores rurais e fazendeiros do município e da região circunvizinha.

\section{Considerações finais}

Neste artigo, abordou-se como o impacto dos agrotóxicos na saúde humana e ambiental conseguiu organizar, inicialmente, um movimento social de vigilância do seu "uso eabuso" e, posteriormente, no processo de implementação, as instituições e populares participantes ampliaramno para "movimento pelo desenvolvimento sustentável de Lucas do Rio Verde e região".

Para tanto, foi necessário desenvolver ações partici pativas de vigilância em saúde-ambiente, em estreita associação com os afetados pelos agrotóxicos e com as entidades e grupos organizados que participaram do processo de conhecimento técnico e social sobre 0 acidente. Espera-se que os partici pantes tenham se apropriado da técnica estratégia de provável controle social sobreo desenvolvimento insustentável da região, para transformá-lo.

Mostrou-seque, para solucionar este problema complexo analisado, não se "caminha" com metodologia reducionista como a tradicional 
promoção e vigilância à saúde, carecendo da participação da comunidade, não como mero gesto ético ou político, mas como uma mudança que pode dar substância aos processos de investigação científica, pois os conhecimentos e práticas do cotidiano local são fundamentais no discernimento das informações que devem ser consideradas na formulação das políticas públicas.

No processo de discussão da agricultura esua interface com a saúde do ambiente, do trabalhador, de sua família e da população, é necessário o exercício de uma abordagem intersetorial e multidisciplinar, envolvendo pelo menos as áreas de saúde, agricultura, ambiente, trabalho, universidade e movimento popular/sindical na busca e decisão sobre qual agricultura e/ou ambiente e/ ou vida se deseja para a sociedade. Ainda sugerese que as questões de "saúde-ambiente" devem ser discutidas e enfrentadas de forma articulada com a luta pela democracia e justiça social, na busca de uma "sociedade" que tenha o desenvolvimento sustentável como eixo (democracia, eqüidade ...).

0 processo de produção da agricultura, na busca do desenvolvimento sustentável, deve incorporar, na questão da saúde, as seguintes propostas: a) que o mínimo de impacto à saúde dos trabal hadores, dos animais, dos vegetais, da água e da terra só será possível através de adoção de "tecnologias não poluentes"; b) estímulos aos movimentos pelo desenvolvimento sustentável que busquem controlar e eliminar o "uso e abuso" de agrotóxico na agropecuária, substituindoos por outras técnicas de controle de pragas; c) implantação de sistemas municipais de vigilância em saúde humana e ambiental, participativos eintegradosintraeinterinstitucional; d) implan- tação de Sistema de M onitoramento de Resíduos de Agrotóxicos em águas de córregos, rios, lagos e pântanos em áreas demonoculturas; e) implantação do M onitoramento ou Programa deAnálise de Resíduos de Agrotóxicos em Alimentos (PARA) em todos os estados e municípios, incluindo-se, além das novefrutas/verduras do programa, a água potável, leite, arroz, feijão, soja e carnes; f) estabelecimento de fóruns de elaboração de normas e monitoramento do desenvolvimento sustentável local e regional composto de trabalhadores, consumidores, representantes do Estado e empresários urbano/rurais; g) financiamento público apenas para as agropecuárias que investirem em tecnologia sustentável para soluções agrosanitárias, buscando a eliminação dos resíduos de agrotóxicos nos alimentos e no ambiente.

\section{Colaboradores}

WA Pignati elaborou o projeto de pesquisa, coletou e analisou os dados. JF Cabral coletou os dados e colaborou no movimento. JMH M achado orientou o projeto e participou da análise.

\section{Agradecimentos}

Ao jornalista Paulo Machado (Radiobrás) e ao sindicalista Nilfo Wandscheer (STRLRV) pelas contribuições na pesqui sa-ação e no "movimento pelo desenvolvimento sustentável".

\section{Referências}

1. Picoli F. Amazônia e o capital: uma abordagem do pensamento hegemônico e do alargamento da fronteira. Sinop-M T: Amazônia Editora; 2005.

2. Dores EFGC. Contaminação por herbicida das águas utilizadas para consumo humano em Primavera do Leste, M ato Grosso [tese]. Cuiabá: Instituto de Saúde Coletiva - UFM T; 2000.

3. Freitas CM , Porto M FS, Gómez CM . Acidentes químicos ampliados: um desafio para a saúde pública. Rev Saúde Pública 1995; 29(6): 503-14.

4. Freitas CM, Porto M FS, M achado JM H, organizadores. Acidentes industriais ampliados. Rio de Janeiro: Editora Fiocruz; 2000.
5. Machado JMHM . Violência no trabalho e na cidade: epidemiologia da mortalidade por acidente de trabalho registrado no município do Rio de Janeiro em 1987 e 1988 [dissertação]. Rio de Janeiro: Escola Nacional de Saúde Pública, Fiocruz; 1991.

6. Porto M FS, Freitas CM. Análise de riscos tecnológicos ambientais: perspectiva para o campo da saúde do trabalhador. Cad Saúde Pública 1977; 13(supl 2):59-72.

7. Tambellini AT, Câmara VM . A temática saúde e ambiente no processo de desenvolvimento do campo da saúde coletiva: aspectos históricos, conceituais e metodológicos. Rev C S Col 1998; 3(2): 47-59. 
8. Soares MS, Silva CLPAC, Barreto M GM, Baptista DF, Borges DA. Solução de problemas em saúde e ambiente: ciência pós-normal e comunidade ampliada de pares em um município brasileiro de pequeno porte. Rev C S Col 1998; 3(2): 115-26.

9. Herculano S, Freitas CM, Porto M FS. Introdução: qualidade de vida e riscos ambientais como um campo interdisciplinar em construção. In: HercuIano S, Freitas CM, Porto M FS, organizadores. Qualidade de vida \& riscos ambientais. Niterói: EdUFF; 2000. p. 17-26.

10. Augusto LG, Florêncio L, Carneiro RM, organizadores. Pesquisa(ação) em saúdeambiental: contexto - complexidade- compromisso social. Recife: Editora Universitária UFPE; 2001.

11. M inayo MCS, M iranda AC. Saúde e ambiente sustentável: estreitando nós. Rio de Janeiro: Editora Fiocruz; 2002.

12. Breilh J. De la vigilância convencional al monitoreo participactivo. Rev C S Col 2003; 8(4): 937-51.

13. Machado JM H, Porto M FS, Freitas CM. Perspectivas para uma Análise Interdisciplinar e Participativa de Acidentes (AIPA) no contexto da indústria de processo. In: Freitas CM , Porto M FS, M achado JM H, organizadores. Acidentes industriais ampliados. Rio de Janeiro: Editora Fiocruz; 2000. p. 49-81.

14. Thiollent M . M etodologia da pesquisa-ação. São Paulo: Cortez;1986.

15. M inayo M CS. Hermenêutica-dialética como caminho do pensamento social. In: M inayo MCS, Deslandes SF, organizadores. Caminhos do pensamento: epistemologia e método. Rio de Janeiro: Editora Fiocruz; 2002. p. 83-107.

16. Garcia EG. Segurança esaúdeno trabalho rural: a questão dosagrotóxicos. São Paulo: M TE/FU N DACENTRO; 2001.

17. Cunha M LF. D eterminação de resíduos de pesticidas em sedimentos dos principais rios do pantanal mato-grossense [dissertação]. Cuiabá: Instituto de Saúde Coletiva/UFM T; 2003.

18. Picoli F. Amazônia: A ilusão da terra prometida. SinopMT: Amazônia Editora; 2004.

19. Pignati WA, M achado JM H M . Riscos e agravos à saúde e à vida dos trabal hadores das indústrias madeireiras de M ato Grosso. Rev C S Col 2005; 10(4):961-73.

20. Garcia EG. Aspectos de prevenção e controle de acidentes no trabalho com agrotóxicos. São Paulo: M TE/FUN DACENTRO; 2005.

21. Perez F, Oliveira-Silva JJ, Della-Rosa HV, Lucca SR. Desafios ao estudo da contaminação humana e ambiental por agrotóxicos. Rev C S Col 2005; 10(supl out/ dez): 27-37.

22. Stoppelli IM BS, Magalhães CP. Saúde e segurança alimentar: a questão dos agrotóxicos. Rev C S Col 2005; 10(supl out/dez):91-98.
23. Silva JM, Novato-Silva E, Faria HP, Pinheiro TMM . Agrotóxico e trabalho: uma combinação perigosa para a saúde do trabalhador rural. Rev C S Col 2005; 10(4):891-904.

24. SINDAG. Dados apresentados pelo Sindicato Nacional das Indústrias de Defensivos Agrícolas. In: Seminário Nacional Sobre Agrotóxicos, Saúde e Ambiente. Organizado pela ANVISA e SES/PE/Olinda; outubro 2005; Brasília.

25. Mato Grosso, Instituto de Defesa Agropecuária de $M$ ato Grosso (INDEA). Relatório de consumo de agrotóxico em M ato Grosso durante o ano de 2005. Cuiabá: INDEA -MT; 2006.

26. Brasil, MAPA. Brasil, série histórica de área plantada; série histórica de produção agrícola; safras 1999 a 2005. [acessado 2006 Jul 05]. Disponível em: www.mapa.gov.br

27. Mato Grosso. Anuário Estatístico do Estado de Mato Grosso. Cuiabá: Secretaria de Estado de Planejamento e Coordenação Geral; 2006.

28. Prefeitura M unicipal de Lucas do Rio Verde. Dados estatístico municipal - Relatório. Lucas do Rio Verde M T: Prefeitura; 2006.

29. SINDAG - Sindicato Nacional das Indústrias de DefensivosAgrícolas. Dados deutilização deagrotóxico. [acessado 2006 M ai 05]. Disponível em: www.sindag.com.br

30. Chaim A. Tecnologia de aplicação de agrotóxicos: fatores que afetam a eficiência e o impacto ambiental. In: Silva CM M S eFay EF. Agrotóxicos \& Ambiente. Brasília: Embrapa; 2004. p. 289-317.

31. Mato Grosso, SUS/SINAN. Dados de notificação do Sistema Nacional de Agravos Notificáveis da Secretaria Estadual de Saúde-M T. [acessado 2006 Jun 05]. Disponível em: www.saúdemt.gov.br

32. Brasil, M inistério da Saúde(M S). Normas técnicas para vigilância epidemiológica. [acessado2006] un 22]. Disponível em: www.saúde.gov.br

33. Brasil, Agência Nacional de Vigilância Sanitária (AN VISA). Leis e N ormas Técnicas sobre comercialização, monografias, uso, toxicidade, classificação de agrotóxicose coleta deamostras para resíduos. [acessado 2006 Jun 22]. Disponível em: www.anvisa.gov.br

34. Santos M . O retorno do território. In: Santos M, Souza M AA, Silveira M L. Território, globalização efragmentação. 4a ed. São Paulo: Hucitec; 1998. p. 15-20.

35. Freire P. Conscientização: teoria e prática da libertação. São Paulo: Ed. M oraes; 1980.

36. Brasil, Rabiobrás. A ameaça do agrotóxico: a cidade pulverizada com o veneno. [2006 jun 22]. Disponível em: www.radiobras.gov.br/especiais/agrotoxico/\# ou www.agenciabrasil.gov.br/listagem-grandes-reportagens

Artigo apresentado em 20/01/2006

Aprovado em 16/06/2006

Versão final apresentada em 31/08/2006 